2. Вершинин Б.И., Попов Л.Е., Постников С.Н., Слободской М.И. Состояние души. Беседы о педагогике как науке о путях реализации функциональных возможностей мозга. [ Текст ] / Б.И. Вершинин., Л.Е.Попов, С.Н. Постников, М.И.Слободской. - Томск, 2006.

Приложение 1

Работы учащихся на тему: «Причины феодальной раздробленности»
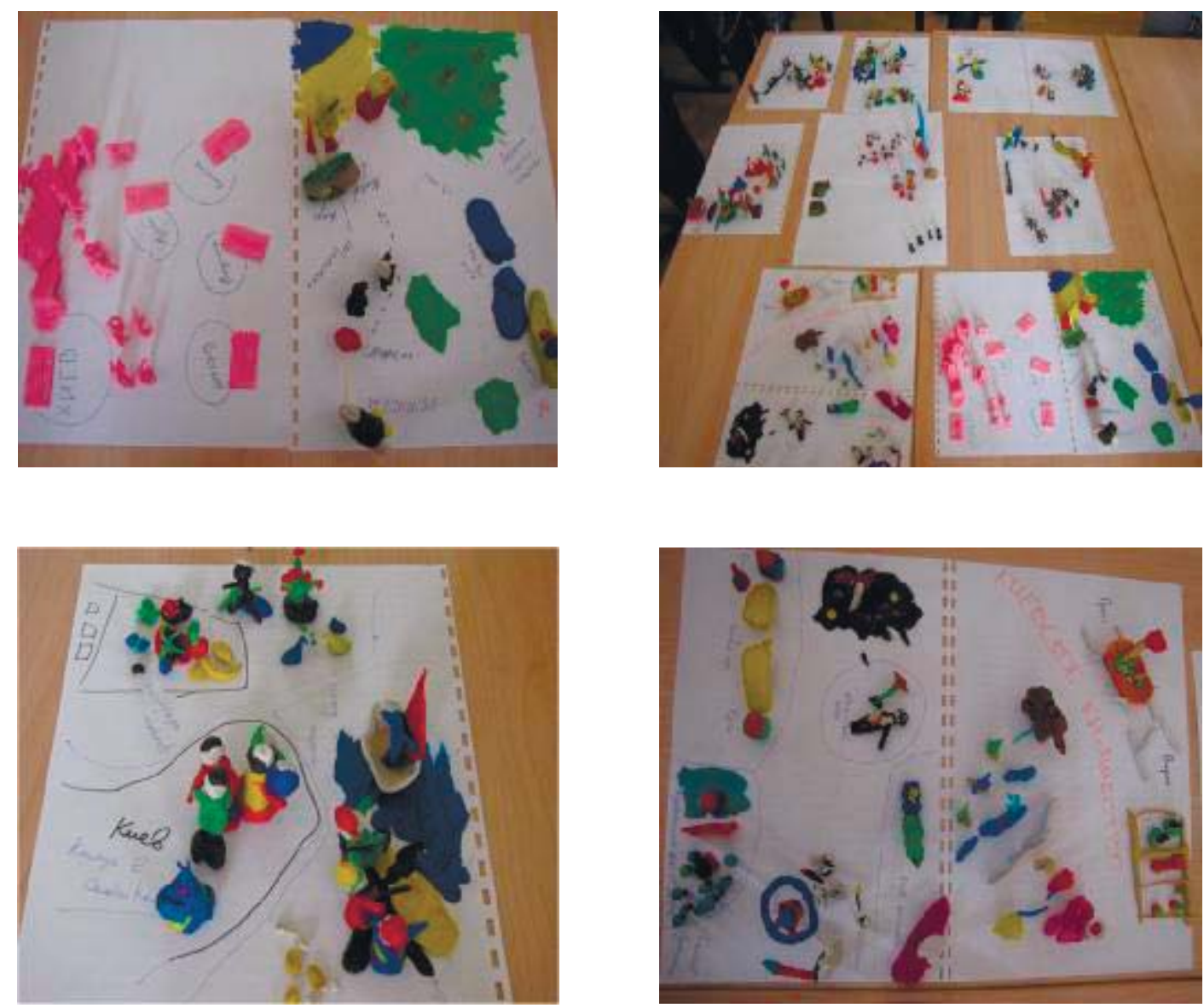

\title{
Собственный сайт отеля как особый вид EDS и инструмент продажи
} гостиничных услуг

Чернов Д.С., магистрант, Санкт-Петербургский государственный экономический университет,

2. Санкт-Петербург

E-mail: helene8@yandex.ru

Научный руководитель: к.с.н., доцент Печерица Е.В.

Учитывая темпы прогрессивного развития индустрии гостеприимства и туристического рынка, сайт отеля становится не только визитной карточкой объекта, но и эффективным каналом продаж. Основная задача официального сайта гостиницы обеспечить клиента всей необходимой информацией об объекте, предоставить 
возможность проверки наличия мест в гостинице на интересующие его даты и иметь возможность забронировать номер по цене не хуже, чем в электронных каналах продаж.

Сайт отеля — это окно с информацией, через которое отель видят гости, и через который должно совершаться основное количество самостоятельных бронирований.

Для того, чтобы быть эффективным инструментом продаж, сайт отеля должен выполнять ряд задач:

Таблица 1

Задачи, которые должен решать сайт отеля

\begin{tabular}{|l|l|}
\hline Задачи & Описание \\
\hline $\begin{array}{l}\text { Пдерживать } \\
\text { посетителей }\end{array}$ & $\begin{array}{l}\text { Полезный и функцинальный контент позволит заметно увеличить среднее } \\
\text { время пребывания пользователя на странице. В первую очередь, речь идет о } \\
\text { качественных фотографиях отеля и оригинальных, которые способны оказывать } \\
\text { сильное воздействие на потенциального клиента. }\end{array}$ \\
\hline $\begin{array}{l}\text { Мотивировать к } \\
\text { бронированию }\end{array}$ & $\begin{array}{l}\text { Сайт отеля должен побуждать потенциальных клиентов забронировать номер. } \\
\text { Данная процедура должна быть простой и понятной. Для многих интернет- } \\
\text { ресурсов отеля свойственна высокая степень отказов - ситуаций, когда } \\
\text { пользователь уходит с сайта, так и не кликнув по какой-либо ссылке. Это } \\
\text { говорит о том, что контент, дизайн, структура или иная составляющая сайта не } \\
\text { мотивируют пользователя к бронированию. }\end{array}$ \\
\hline $\begin{array}{l}\text { Снижать } \\
\text { стоимость } \\
\text { привлечения } \\
\text { гостей в отель }\end{array}$ & $\begin{array}{l}\text { Самое большое преимущество сайта перед электронными каналами продаж - } \\
\text { это отсутствие комиссионных выплат за совершенные бронирования. } \\
\text { Исключение составляют те случаи, когда на сайт отеля устанавливается модуль } \\
\text { бронирования от компаний, которые работают на комиссионной основе. }\end{array}$ \\
\hline
\end{tabular}

Составлено на основе: [1] и [2].

Решение данных задач повысит количество прямых бронирований, что позволит отелю не выплачивать комиссионное вознаграждение, а повысить размер получаемого дохода.

Таблица 2

Распространенные ошибки сайтов отелей

\begin{tabular}{|l|l|}
\hline Ошибки & Описание \\
\hline длишком & $\begin{array}{l}\text { Многие отельеры перегружают сайты обилием анимированных элементов и } \\
\text { аудиоматериалов, что отрицательно сказывается на времени загрузки сайта, которое } \\
\text { должно быть сведено к минимуму. Посетитель просто уйдет, если все ключевые } \\
\text { элементы сайта не загрузятся в течение нескольких секунд. Высокая скорость загрузки } \\
\text { позволит снизить процент отказов потенциальных клиентов и повысить конверсию } \\
\text { посетителей в гостей. }\end{array}$ \\
\hline $\begin{array}{l}\text { Слишком } \\
\text { сложно }\end{array}$ & $\begin{array}{l}\text { Многоуровневое меню значительно усложняет процесс навигации. Интуитивно } \\
\text { понятная и привычная навигация способствует продолжительному посещению } \\
\text { туриста сайта отеля. Помимо прочего, часто встречаются сайты, где изначально не } \\
\text { совсем понятно, как добраться до контента. Основная информация, необходимая } \\
\text { клиенту перед бронированием сводится к трем пунктам: местоположение отеля, } \\
\text { наглядное описание номеров и стоимость. Именно на эту информацию необходимо } \\
\text { делать акцент, чтобы пользователь без труда мог ее найти. }\end{array}$ \\
\hline
\end{tabular}

Составлено на основе: [3] и [4]. 
Исправление или избегание данных ошибок повысит количество прямых бронирований, что позволит отелю не выплачивать комиссионное вознаграждение, а повысить размер получаемого дохода.

Большое значение имеет структура сайта гостиницы, максимально простая и интуитивно-понятная, которая будет удобна для посетителей отеля. Сайт должен быть наиболее информативным, чтобы клиенты нашли ответы на вопросы, возникающие при бронировании гостиничных услуг.

Таблица 3

Разделы сайта отеля

\begin{tabular}{|l|l|}
\hline $\begin{array}{l}\text { Разделы } \\
\text { сайта }\end{array}$ & Что должно быть представлено \\
\hline $\begin{array}{l}\text { Главная } \\
\text { страница }\end{array}$ & $\begin{array}{l}\text { Привлечь внимание клиентов рекомендуется с помощью размещения слайдера с } \\
\text { качественными фотографиями, информацию об акциях и скидках, грамоты или } \\
\text { награды за предоставление качественного сервиса. }\end{array}$ \\
\hline Контакты & $\begin{array}{l}\text { Это позволит клиенту сразу оценить местоположение предприятия } \\
\text { гостеприимства. Рекомендуется разместить интерактивную карту от Gооgle или } \\
\text { Яндекс, чтобы гостям по было проще найти отель. Здесь должны быть } \\
\text { представлены номера телефонов и етаіl. }\end{array}$ \\
\hline Номера & $\begin{array}{l}\text { Эта наиболее важный блок для посетителя сайта. Рекомендуется использовать } \\
\text { только качественные фотографии номеров отеля. Необходимо наиболее подробно } \\
\text { описать каждый тип номера, указать услуги отеля, которые предоставляются при } \\
\text { проживании в нем. }\end{array}$ \\
\hline Об отеле & $\begin{array}{l}\text { На этой странице сайта гостиницы можно опубликовать информацию об истории, } \\
\text { достижениях и наградах, интересных событиях, связанные с отелем и любая } \\
\text { другая информация, интересная посетителю. }\end{array}$ \\
\hline Услуги & $\begin{array}{l}\text { Подробное описание услуг гостиницы и их стоимость, как например, трансфер, } \\
\text { Wі-fi, бесплатная охраняемая парковка, хранение багажа, тренажерный зал и т. д. }\end{array}$ \\
\hline Отзывы & $\begin{array}{l}\text { Наличие раздела на сайте, где клиенты могут ознакомиться с оставленными } \\
\text { отзывами, а также написать свои. }\end{array}$ \\
\hline
\end{tabular}

Составлено на основе: [5] и [6].

Данная структур сайта отеля является наиболее оптимально, поскольку обеспечивает четкое и интуитивно понятное представление информации для клиентов. Это повышает вероятность удержания клиента на сайте, и совершить прямое бронирование на сайте отеля.

Сайт для отеля должен обладать фирменным стилем, иметь логотип, привлекать внимание различными элементами веб-дизайна. Очень важно размещать только высококачественные фотографии гостиницы, номеров и кухни, используя слайдеры и тизеры. Они должны показать чистоту и комфорт номеров, ведь именно это влияет на принятие решения о выборе места для отдыха и ночлега [7].

Наилучшим решением для того, чтобы клиент забронировал услугу на сайте, является установка модуля бронирования. Модуль помогает увеличить количество прямых бронирований, что напрямую поднимает уровень доходности отеля, а также снимает часть затрат. связанных с выплатой комиссионной части электронным каналам продаж в размере 15-20\%. Клиенты отеля в режиме реального времени видят актуальную информацию о ценах и свободных номерах [8].

Таким образом, задача сайта отеля и модуля бронирования в частности подвигнуть гостя к бронированию гостиничных услуг, т.е. конвертировать. 
Для повышения вероятности того, что клиент останется на сайте самого отеля, необходимо реализовать следующие условия, перечисленные в таблице 4.

Условия необходимые для увеличения конверсии сайта отеля

\begin{tabular}{|c|c|}
\hline Условия & Описание \\
\hline $\begin{array}{l}\text { Модуль } \\
\text { бронирования }\end{array}$ & $\begin{array}{l}\text { Должен располагаться на видном месте, чтобы клиент мог в любой } \\
\text { момент посмотреть интересующие его даты. }\end{array}$ \\
\hline $\begin{array}{l}\text { Привлекательность } \\
\text { сайта }\end{array}$ & $\begin{array}{l}\text { Наличие качественных широкоформатных фотографий отеля, } \\
\text { специально разработанный дизайн, крупный шрифт для удобства } \\
\text { восприятия текстовой информации клиентом. }\end{array}$ \\
\hline Информация & $\begin{array}{l}\text { Является полной, понятной и достоверной. Клиент может ознакомиться } \\
\text { с номерным фондом, расположением, а также со всеми услугами, } \\
\text { представляемыми предприятием гостеприимства: трансфер, питание, } \\
\text { консьерж, конференц-возможности и т.д. }\end{array}$ \\
\hline $\begin{array}{l}\text { Гибкая политика } \\
\text { спецпредложений }\end{array}$ & $\begin{array}{l}\text { Наличие тарифов, с различными условиям, использующимися } \\
\text { адекватно сезонности: невозвратный, раннего бронирования, } \\
\text { стандартный, } 3 \text { ночи по цене } 2 \text { и др. }\end{array}$ \\
\hline $\begin{array}{l}\text { Мультиязычность и } \\
\text { мультивалютность }\end{array}$ & Позволит привлечь, и удержать клиентов из разных стран. \\
\hline Социальные сети & $\begin{array}{l}\text { Отель должен быть представлен в различных социальных сетях: } \\
\text { Вконтакте, Facebook, Twitter, Foursquare. С их помощью можно } \\
\text { размещать информацию об акциях, промо-коды, общаться с клиентами } \\
\text { и др. }\end{array}$ \\
\hline Промо-код & $\begin{array}{l}\text { Клиент, который введёт его в специально поле на сайте, получает } \\
\text { скидку на проживание. Промо-коды хорошо размещать в социальных } \\
\text { сетях, т.к. это позволяют увидеть отдачу от использования социальных } \\
\text { сетей. }\end{array}$ \\
\hline Отзывы & $\begin{array}{l}\text { Наличие раздела на сайте, где клиенты могут ознакомиться с } \\
\text { оставленными отзывами, а также написать свои. }\end{array}$ \\
\hline
\end{tabular}

Составлено на основе: [8] и [9].

Перечисленные в таблице условия позволят привлечь клиентов с EDS на собственный сайт отеля, и как следствие, повысить его конверсию.

Электронные каналы продаж и собственный сайт отеля выполняет не только презентационную функцию, но и функцию продажи. Число бронирований через данные платформы неуклонно растет, поэтому чрезвычайно важно опубликовать профиль отеля в электронных каналах продаж и запустить собственный сайт отеля. Однако, чем большая доля осуществлённых on-line бронирований будет приходиться на собственный сайт отеля, а не на электронные каналы продаж, тем выше будут доходы предприятия гостеприимства, за счет выплаты комиссионного вознаграждения в меньшем объеме.

\section{Список литературы:}

1. Печерица Е.В., Шевченко М.И. Инновационные технологии в гостиничном бизнесе. монография / Санкт-Петербургский государственный университет сервиса и экономики. Санкт-Петербург, 2013. 135 с.

2. Печерица Е.В. Позиционирование предприятий индустрии гостеприимства в условиях конкуренции. монография / Е.В. Печерица; М-во образования и науки 
Российской Федерации, Федеральное агентство по образованию, Санкт-Петербургский гос. ун-т сервиса и экономики. Санкт-Петербург, 2010. 163 с.

3. Печерица Е.В. Категоризация и оценка качества гостиничных услуг. монография / Санкт-Петербургский государственный университет сервиса и экономки. Санкт-Петербург, 2010. 239 с.

4. Рубан Д.А. Инновационный менеджмент в туризме: направления и управленческие действия//Вестник УрФУ. Серия экономика и управление. 2015. № 1. С. 114-126.

5. Печерица Е.В. Повышение конкурентоспособности отелей на основе применяемой ими стратегии (на примере санкт-петербурга). Технико-технологические проблемы сервиса. 2013. № 3 (25). С. 79-84.

6. Печерица Е.В. Концептуальные основы управления конкурентоспособностью субъектов гостиничного бизнеса. Министерство образования и науки Российской Федерации, Санкт-Петербургский государственный экономический университет, Кафедра рекреации и туризма. Санкт-Петербург, 2014.

7. Печерица Е.В. Особенности рекламы в гостиничном бизнесе. Российское предпринимательство. 2012. № 12. С. 153-159

8. Печерица Е.В., Чернов Д.С. Электронные каналы продаж (eds) как способ продвижения гостиничных услуг. Управление продажами. 2015. № 6. С. 416-427.

9. Печерица Е.В., Чернов Д.С. Социальные сети как способ продвижения гостиничных услуг. Технико-технологические проблемы сервиса. 2015. № 3 (33). С. 9399.

\section{Повстанчество в Сунтарском улусе 1922-1923 гг.}

\section{Яковлев А.Н., студент, Северо-Восточный федеральный университет, 2. Якутск E-mail: aleksandr_yakovlev_97@mail.ru}

Научные руководители: к.и.н., стариий преподаватель Акимова В.С., стариий преподаватель Андреев А.П.

Когда в Сунтарском улусе вспоминают про Гражданскую войну в Якутии, то большинство обывателей ограничиваются рассказами «о бандите» Павлове и о его расстрелах в с. Тойбохой. Это далеко не так, поэтому в этой статье попытаемся объективно изложить суть тех далеких и драматических по-своему содержанию событий, которые в свое время привели к самым трагическим результатам для обеих противоборствующих сторон.

После окончательного установления Советской власти на территории Сунтарского улуса (в те времена состоящих из двух улусов Сунтарского и Хочинского) в 1922 г. произошел один из трагических эпизодов Гражданской войны, известный как «повстанчество».

Причинами повстанчества в Вилюйском округе и в частности в Сунтарском улусе относят политику ВЧК РСФСР в лице отдельных ее сотрудников на местах, допускавших неправомерные и ошибочные действия, незнание местной специфики. 